\title{
Homologies of the Anterior Teeth in Indriidae
}

\author{
PHILIP D. GINGERICH \\ Museum of Paleontology, The University of Michigan, Ann Arbor, Michigan 48109
} KEY WORDS Lemuriform primates - Dental scraper · Dental
homologies . Indriidae - Avahi

\begin{abstract}
Schwartz (74) proposed revised homologies of the deciduous and permanent anterior teeth in living lemuriform primates of the family Indriidae. Gingerich ('77) described a juvenile specimen of Avahi and emphasized the importance of functional integrity in controlling the pattern of dental reduction in primates, neither of which supports Schwartz's interpretation. Schwartz ('78) recently reiterated his position without adequately discussing the Avahi evidence and the functional basis that probably controls dental reduction. Avahi has a deciduous dentition intermediate in morphology between that of Lemuridae and Indriidae, and similar to both. Thus the lower deciduous dental formula of Indriidae is probably 2.1.3, which is the typical and maximum deciduous complement known in living and fossil lemuriform primates. The formula of the lower permanent dentition in Indriidae is thus $2 \cdot 0 \cdot 2 \cdot 3$.
\end{abstract}

Most lemuriform primates have an anterior dental scraper or tooth comb consisting of six teeth: two incisors on each side, bordered by the canines. Indriidae have only four of the original six teeth in the comb, which are generally interpreted to be homologous with the original four incisors. Schwartz ('74) recently revived the hypothesis that the four teeth in the indriid tooth comb are two incisors bordered by canines, rather than four incisors. Schwartz's hypothesis implies a pattern of dental reduction in Indriidae involving functional disruption of the tooth comb as incisors were lost from the center, rather than from the edges, of the original six-toothed comb.

In an earlier paper I described a specimen preserving the deciduous dentition of the smallest and least well known indriid, Avahi (Gingerich, '77). This specimen shows that the deciduous dentition is intermediate between that of Lemuridae and typical Indriidae, yet similar to both. Responding to this paper, Schwartz ('78) apparently misunderstood the reasons I advanced for regarding the third deciduous tooth in Avahi as a deciduous canine rather than a premolar. Schwartz ('78) also avoids mention of the functional basis supporting dental reduction from the edges rather than the middle of the tooth comb. It is not necessary here to repeat the discussion of dental homologies and dental reduction presented previously (Gingerich, '77). The purpose of this note is simply to restate more clearly the viewpoint I expressed regarding homology of the third deciduous tooth in Avahi.

\section{DECIDUOUS DENTITION OF AVAHI}

The lower deciduous dentitions of Lemuridae, represented by Hapalemur, and Indriidae, represented by Avahi and Propithecus, are shown in figure 1. Hapalemur has two deciduous incisors bordered by a deciduous canine in each mandibular ramus, making a total of six teeth in the deciduous tooth comb. Three deciduous premolars are also present, giving a full lower deciduous formula of $2 \cdot 1.3$. This is the maximum number of deciduous teeth known at each position for any primate. Even the primitive lemuriform primates Adapis and Notharctus had this deciduous dental formula (Stehlin, '12: pp. 1178-1179; Gregory, '20: p. 150).

Avahi and Propithecus also have six deciduous teeth in each mandibular ramus, with the fourth, fifth, and sixth clearly being premolars. The first deciduous tooth is clearly an incisor. Schwartz and I differ in interpreting 

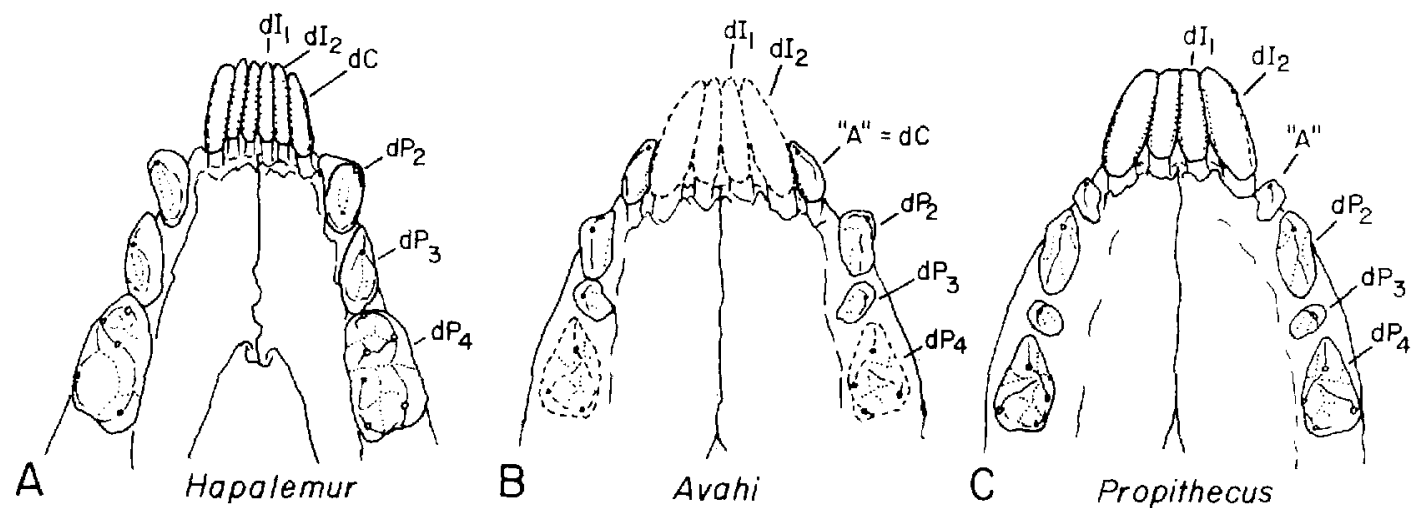

Fig. 1 Comparison of the lower deciduous dentition of three lemuriform primates, in occlusal view, brought to same size for ease of comparison. A. Lemurid Hapalemur, with agreed tooth homologies indicated. B. Indriid Avahi, with conventional homologies advocated here. C. Indriid Propithecus, with conventional homologies advocated here. Schwartz (74, '78) identifies tooth " $\mathrm{A}$ " in Indriidae as $\mathrm{dP}$ because the tooth labelled $\mathrm{dI}_{2}$ resembles morphologically $\mathrm{dC}$ in Hapalemur and other Lemuridae. However, tooth " $\mathrm{A}$ " in Avahi is intermediate in morphology between dC of Lemuridae and tooth "A" in Propithecus and Indri. It also occupies the same relative position. Therefore, tooth "A" in Indriidae is almost certainly the deciduous canine. Figures drawn from specimens illustrated in Gingerich ('77).

the homologies of the second and third deciduous teeth. Schwartz ('74, '78) argues that the shape and eruption (which are probably correlated) of the second deciduous tooth in Propithecus are most similar to those of the third deciduous tooth in lorisids or lemurids (such as Hapalemur), and he thus regards the second tooth in Propithecus as a deciduous canine. Osborn ('78) has argued similarly that the permanent tooth conventionally regarded as $\mathrm{P}_{3}$ in Indri should be called a lower canine because its shape is caniniform. Taking this one step further, similarity in shape would suggest that the lateral tooth in the tooth comb of the condylarth Thryptacodon is homologous with the canine in the lemur tooth comb, but its position and the shape of the true canine tooth behind it clearly indicate that the lateral tooth is $I_{3}$, even though it is shaped like the lower canine of a lemur (Gingerich and Rose, '79).

Similarity in shape is not the only indication of homology. The recognizing criteria used in ascertaining homologues are similarities of all sorts, be they of appearance, material composition, positional relationship with other features, embryological, or whatever (Bock, '73: p. 387). Shape is no more reliable than position as an indicator of homology. The position of the third deciduous tooth in Avahi and Propithecus, tooth "A", being third in a six-tooth deciduous series, suggests that tooth " $\mathrm{A}$ " is homologous with the deciduous canine in Hapalemur. This view is further strengthened by the shape of tooth " $\mathrm{A}$ " in Avahi, which is intermediate in morphology between the deciduous canine of Hapalemur and tooth " $\mathrm{A}$ " in Propithecus, yet similar to both. Hence, both position and shape suggest that the third deciduous tooth in Indriidae is a deciduous canine.

The reasoning presented above is the same as in my previous paper (Gingerich, ' 77 ), and I should clarify this by pointing out a critical quotation misattributed by Schwartz ('78). I concluded that tooth "A" in Avahi is a lower deciduous canine "because of its similarity in position and morphology to the lower deciduous canine of Lemuridae" (p. 388) (cf., quotation cited by Schwartz ['78: p. 24]). I stated that "the specimen in question does not show the wear found in Schwartz's Age Group II Indriidae and its position cannot be attributed to mesial drift associated with wear" (p. 388) because wear and mesial drift cannot be used to explain either the crown shape or the position of tooth " $A$ " in this specimen of Avahi, even though it is in Age Group II and might be expected to have had a heavily worn tooth "A".

My observations on the only described specimen of Avahi preserving anterior deciduous teeth do not support Schwartz's ('78) assertion that the deciduous tooth " $A$ " is greatly displaced from life position. Unless Schwartz knows of new specimens showing that this de- 
ciduous dentition is unrepresentative of Avahi, I think that the evidence presented previously (Gingerich, '77) and in figure 1 supports interpretation of the deciduous dental formula on Indriidae as 2.1.3. The deciduous canine in Indriidae is not replaced in the permanent dentition, showing that dental reduction occurred at the edges of the tooth comb and not in the middle of this integrated functional unit. In addition, one of the deciduous premolars is not replaced, making the formula of the lower permanent dentition $2 \cdot 0 \cdot 2 \cdot 3$ in Indriidae.

\section{LITERATURE CITED}

Bock, W. J. 1973 Philosophical foundations of classical evolutionary classification. Syst. Zool., 22: 375-392.
Gingerich, P. D. 1977 Homologies of the anterior teeth in Indriidae and a functional basis for dental reduction in primates. Am. . Phys. Anthrop., 47: 387-394.

Gingerich, P. D., and K. D. Rose 1979 Anterior dentition of the Eocene condylarth Thryptacodon: remarkable convergence with the tooth comb of lemurs. J. Mammal., 60: 16-22.

Gregory, W. K. 1920 On the structure and relations of Notharctus, an American Eocene primate. Mem. Amer. Mus. Nat. Hist. (N.S.), 3: 49.243 .

Osborn, J. W. 1978 Morphogenetic gradients: fields versus clones. In: Development, Function, and Evolution of Teeth. P. M. Butler and K. A. Joysey, eds. Academic Press, New York, pp. 171-201.

Schwartz, J. H. 1974 Observations on the dentition of the Indriidae. Am. J. Phys. Anthrop., 41: 107-114.

- 1978 Homologies of the toothcomb. Am. J. Phys. Anthrop., 49: 23-30.

Stehlin, H. G. 1912 Die Säugetiere des schweizerischen Eoceans. Critischer Catalog der Materialen. Adapis. Abh. Schweiz. Pal. Ges, 38: 1165-1298. 